\title{
Kempfidris, a new genus of myrmicine ants from the Neotropical region (Hymenoptera: Formicidae)
}

\author{
Fernando FERNÁNDEZ ${ }^{1}$, Rodrigo M. FEITOSA ${ }^{2} \&$ John $^{2}$ LATTKE $^{3}$ \\ ${ }^{1}$ Instituto de Ciencias Naturales, Universidad Nacional de Colombia, Apartado 7495, Bogotá D.C., \\ Colombia. E-mail: ffernandezca@unal.edu.co \\ urn:lsid:zoobank.org:author:6F96DA0B-5889-40F4-A946-DBB05FB77F7B \\ ${ }^{2}$ Departamento de Zoologia, Universidade Federal do Paraná, Caixa Postal 19020, 81531-980, \\ Curitiba, PR, Brazil. E-mail: rsmfeitosa@gmail.com \\ urn:1sid:zoobank.org:author:443A72A7-196F-47FF-A02D-0B5F4B48D8B3 \\ ${ }^{3}$ Universidad Nacional de Loja, Dirección de Investigación - BioS, Ciudad Universitaria, \\ La Argelia, Loja, Ecuador. E-mail: piquihuye@gmail.com \\ urn:1sid:zoobank.org:author:7AE0D94C-619B-4E77-B16F-3F18731EE390
}

\begin{abstract}
The new genus Kempfidris gen. nov. is described based on the workers of a single species, $K$. inusualis comb. nov., from Brazil, Ecuador, and Venezuela. Kempfidris inusualis comb. nov. was originally described by Fernández (2007) and provisionally placed in Monomorium awaiting a better understanding of the internal relationships in Myrmicinae. Kempfidris gen. nov. has a series of distinctive morphological characters including the mandibular configuration, vestibulate propodeal spiracle, propodeal carinae, and cylindrical micro-pegs on the posteromedian portion of abdominal tergum VI and anteromedian portion of abdominal tergum VII. This last trait appears to be autapomorphic for the genus.
\end{abstract}

Key words. Myrmicinae, new genus, Neotropical region, taxonomy

Fernández F., Feitosa R.M. \& Lattke J. 2014. Kempfidris, a new genus of myrmecine ants from the Neotropical region (Hymenoptera: Formicidae). European Journal of Taxonomy 85: 1-10. http://dx.doi.org/10.5852/ejt.2014.85

\section{Introduction}

Due to its large diversity, Myrmicinae Lepeletier, 1835 is the most challenging subfamily in myrmecology regarding its internal relationships and the search for a stable tribal arrangement. Much of the current classification follows the initial proposals of Emery (1921) and Wheeler (1922), with important modifications by Bolton (2003). However, many tribes and some genera are obviously artificial, and given the considerable amount of ongoing research, both basic and applied, involving many taxa from this group, it is important to begin to clarify the internal relationships of this subfamily.

The solenopsidine tribe group, proposed by Bolton (2003) for Solenopsidini Forel, 1893 and Stenammini Ashmead, 1905, is partly diagnosed by a clypeus with a posterior constriction moderately to greatly inserted between the frontal lobes and an elevated and narrow median area, which is usually bicarinate. The same author recognized the Solenopsidini, including the Solenopsis group, characterized by the 
presence of a seta on the anteromedian clypeal margin, and the Carebara group, which lacks the clypeal seta. Subsequent modifications to this proposal include the creation of the tribe Adelomyrmecini Fernández, 2004 (Adelomyrmex Emery, 1897, Baracidris Bolton, 1981 and Cryptomyrmex Fernández, 2004) and an expansion of the concept of Monomorium Mayr, 1855 in the Neotropics (Fernández 2004, 2007). However, there have been no phylogenetic studies evaluating either these proposals or the monophyly and relationships of the solenopsidine group.

Some central problems remain in defining Monomorium and the relationships between the satellite taxa proposed throughout its long taxonomic history, including Monomorium inusuale Fernández, 2007. Recent molecular and morphological phylogenetic studies of ants as a whole have been focused at the subfamily or tribal level, beyond the scope of issues at the generic level (Moreau et al. 2006; Brady et al. 2006; Keller 2011; Moreau \& Bell 2013). Solenopsidini does appear to be polyphyletic in Moreau et al. (2006), but the status of Monomorium remains unclear. According to Brady et al. (2006), Solenopsidini could be monophyletic, but with the inclusion of Myrmicaria Saunders, 1842, whereas the status of Monomorium remains unknown. In Moreau \& Bell (2013), Solenopsidini appears to be monophyletic if Myrmicaria is included, and Monomorium is apparently polyphyletic. Even though these studies did not address the generic level, they do make an unequivocal case for the poor resolution and instability of the relationships between the tribes and genera proposed within the Myrmicinae.

Currently, the Ant Tree of Life project (AToL) team is engaged in the final stages of preparing a presentation of the internal phylogeny of Myrmicinae, and preliminary results corroborate the artificial nature of the cosmopolitan and morphologically diverse genus Monomorium, already suspected by various authors (Bolton 1987; Heterick 2003). In 2007, Fernández described two new species for the Neotropics, including the morphologically peculiar Monomorium inusuale, based on workers collected in forested areas of Brazil (Amazonas and Bahia) and Ecuador. Workers of M. inusuale present a very unusual combination of morphological characters, which led Fernández to question the position of the species within the genus. However, M. inusuale was tentatively assigned to Monomorium until the limits of the heterogeneous myrmicine tribes could be clearly defined.

A reconsideration of the characters defining $M$. inusuale, and its position amongst the solenopsidines, has strengthened the case for recognizing this taxon as a distinct lineage in this group. Here we describe this new monotypic myrmicine genus and provide updated information on its distribution in the Neotropical region. We consider this as one of the many necessary steps to seeking a more stable classification in Myrmicinae.

\section{Material and methods}

The materials studied during this investigation are deposited in the following institutions:

CASC $=$ California Academy of Sciences, San Francisco, CA, USA

DZUP $=$ Coleção Entomológica Pe. Jesus Santiago Moure, Universidade Federal do Paraná, Curitiba, PR, Brazil

ICN = Instituto de Ciencias Naturales, Universidad Nacional de Colombia, Bogotá D.C., Colombia MZSP = Museu de Zoologia, Universidade de São Paulo, SP, Brazil

Scanning electron microscope (SEM) photographs (Fig. 1) were taken at the University of Alberta in Edmonton by Danny Shipley and George Ball. High resolution images (Fig. 2) were obtained using a Leica M125 stereomicroscope attached to a Leica DFC 295 video camera. Photos were combined using Zerene Stacker software at the DZUP. Images were then processed as TIFF files in Adobe ${ }^{\circledR}$ Photoshop $\mathrm{CS}^{\circledR}{ }^{\circledR}$ to enhance parameters of brightness and contrast. Pictures of the Venezuelan specimen (Fig. 3) were taken from AntWeb (www.antweb.org). 


\section{Results}

Class Hexapoda Blainville, 1816

Order Hymenoptera Linnaeus, 1758

Suborder Apocrita Latreille, 1810

Superfamily Vespoidea Latreille, 1802

Family Formicidae Latreille, 1809

Subfamily Myrmicinae Lepeletier, 1835

Tribe incertae sedis

Kempfidris gen. nov.

Figs $1-3$

urn:1sid:zoobank.org:act:B9B9FBA4-E0A5-44A2-BDD1-3C9ADA644AD9

\section{Type species}

Monomorium inusuale Fernández, 2007

\section{Etymology}

It is with great pleasure that we dedicate this new genus to Father Walter W. Kempf (1920-1976) (Fig. 4) for his brilliant, but somewhat short career in ant taxonomy, with special reference to the Neotropical fauna. Besides the many monographs and descriptions of new taxa, Kempf provided the first catalog of Neotropical ants (Kempf 1972), an obligate reference (until recently) for generations of myrmecologists.

\section{Description (worker)}

Antenna 12-segmented, with a well-defined 3-segmented club. Eye reduced to almost indistinct ommatidia, placed just anteriorad of head midlength. Frontal carinae and antennal scrobes absent. Mandible with four teeth: three apical teeth separated from isolated basal tooth by large diastema. Palpal formula 2,1. Clypeus projected anteromedially to form truncate lobe, lobe laterally bluntly angular and medially weakly concave, with distinct median seta and several surrounding setae. Median lobe of clypeus strongly bicarinate, carinae defining elevated area that converges posteriorly to form narrow strip between frontal lobes. Pronotum with anterolateral crest that extends dorsally, delimiting narrow anterior portion of pronotum. Metanotal groove very deep, well-marked. Bulla of metapleural gland large. Propodeum unarmed, declivity surrounded dorsolaterally by a crest, higher laterally than dorsally and joining the small metapleural lobe. Posteromedian portion of abdominal tergum VI and anteromedian portion of abdominal tergum VII with several minute, cylindrical micro-pegs, each bearing a hair on apex, though apparently broken in some.

\section{Remarks}

Kempfidris inusualis comb. nov. was provisionally described in Monomorium (Fernández 2007), but with many doubts due to the poor state of knowledge of the internal relationships in Myrmicinae. Fernández commented on a suggestion by Barry Bolton (pers. comm.) that $K$. inusualis comb. nov. might be a member of Stenammini due to its overall resemblance with members of that tribe. Traits of the frontal lobes and toruli, as well as the clypeal posterior border, would place K. inusualis comb. nov. in the Stenammini as diagnosed in Bolton (2003: 58). However, the first gastral tergite clearly overlaps the first sternite on its ventral surface, and the presence of a single medial clypeal seta indicates that the taxon belongs in the Solenopsidini, again sensu Bolton (2003: 59). We presently prefer to leave Kempfidris gen. nov. as an incertae sedis genus within the Myrmicinae until Ward and collaborators publish the conclusions, including a tribal arrangement, of their ongoing research (P.S. Ward, pers. comm.). 
A reconsideration of this species, given the series of unusual characters it has compared to other myrmicines, argues for recognising it as a distinct lineage. Leaving it in Monomorium only increases the difficulties of defining a monophyletic Monomorium, thus confounding the present situation within those groups. The strongly reduced eyes and the long diastema between the three apical teeth and the basal tooth do not appear to be common in myrmicines. Kempfidris gen. nov. is reminiscent of Cryptomyrmex regarding the mandibular configuration (four teeth with a diastema), clypeal structure (elevated median area), single median seta along the anterior clypeal margin, and reduced number (2) of maxillary palp segments. However, Cryptomyrmex has a different antennal structure (12 segments, the last two forming a club), modified hairs along the mandibular masticatory margin and subcutaneous ommatidia. Reduced eyes can be found in the African fossulatum-group of Monomorium (Bolton 1987), as well as in Carebarella.
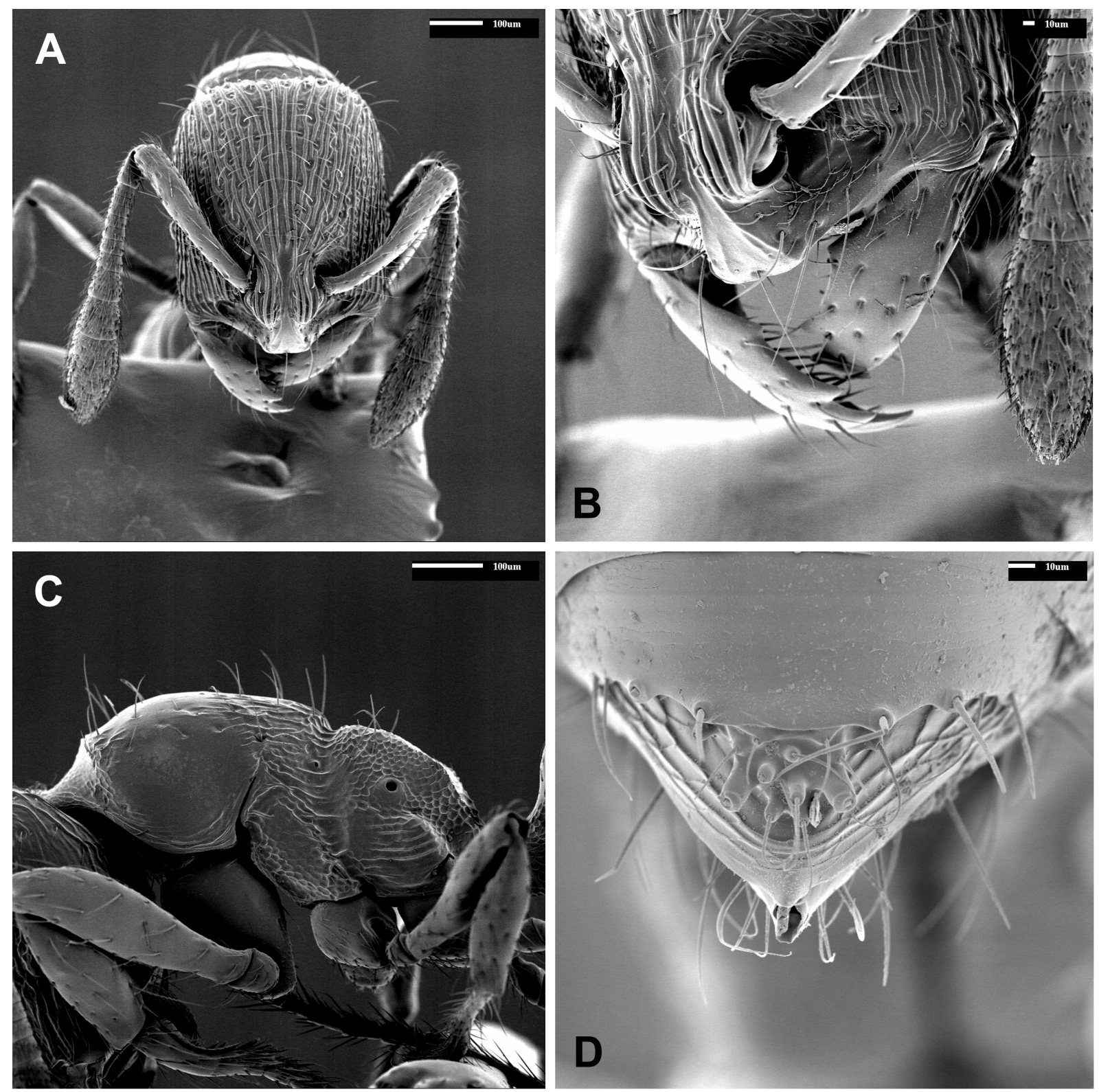

Fig. 1. Kempfidris inusualis (Fernández, 2007) comb. nov., worker from Benjamin Constant, Amazon, Brazil (ICN). SEM photographs. A. Head in full face view. B. Head in dorsal oblique view. C. Mesosoma in lateral view. D. Apex of metasoma showing the cylindrical micro-pegs. 
The most outstanding feature of Kempfidris gen. nov. is the series of minute, hair-bearing tubercles or cylindrical pegs on the abdominal apex. Most are concentrated on the anteromedian portion of the pygidium and some on the posteromedian portion of abdominal tergite VI, a position that would coincide with the position of the pygidial gland, which opens between abdominal tergites VI and VII (Billen 2009). The structure of the micropegs with their associated hairs also hints at some sort of glandular function, or possibly a mechano-reception function during stinging, but a more convincing explanation will only be possible after a histological study. Whatever the function of these tubercles, they appear to be an autapomorphic structure, absent in other Myrmicinae and probably in other ants as well. In

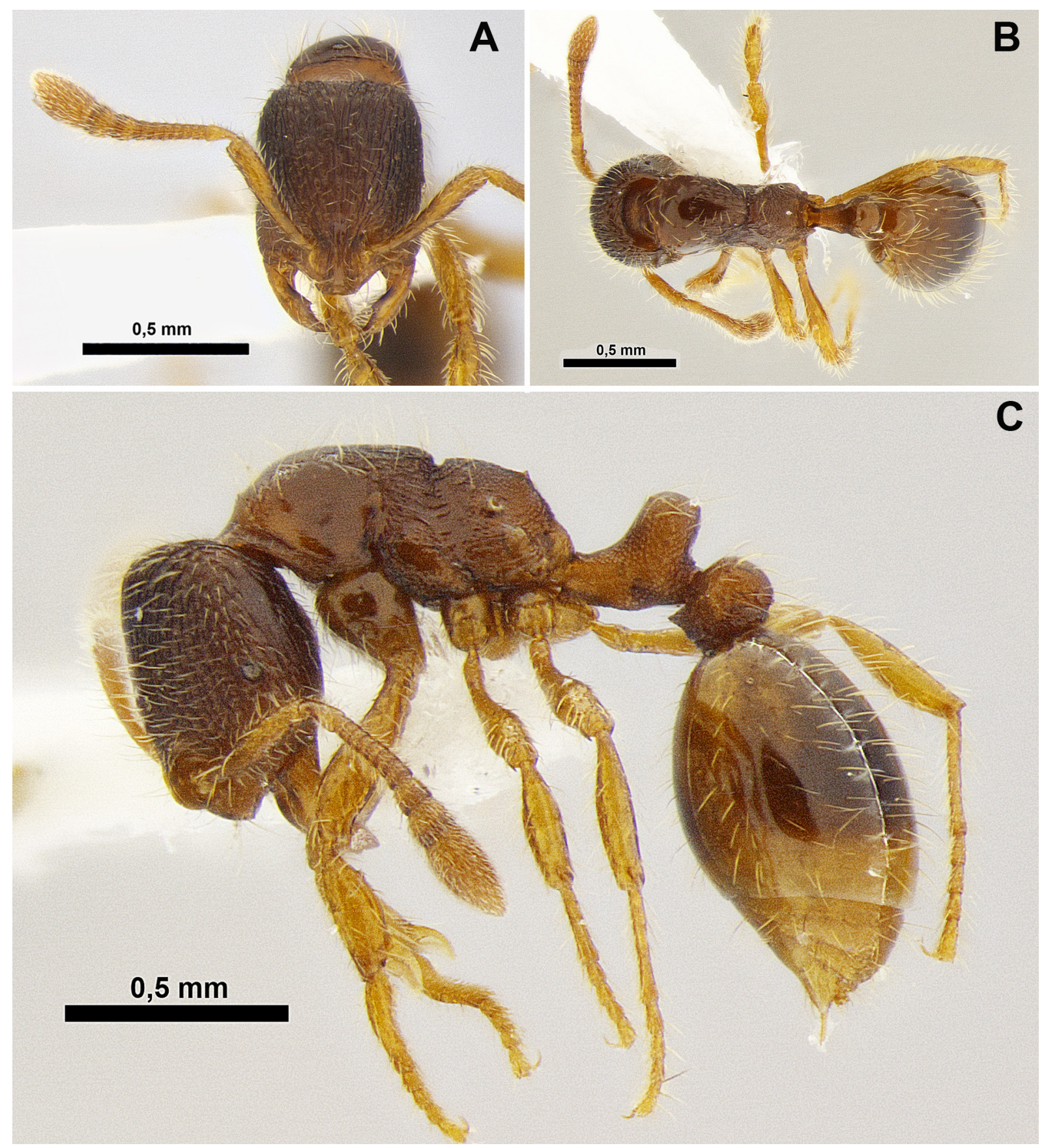

Fig. 2. Kempfidris inusualis (Fernández, 2007) comb. nov., worker from Porto Velho, Rondônia, Brazil (DZUP). High-resolution images. A. Head in full face view. B. Body in dorsal view. C. Body in lateral view. 
ants, the most structurally similar cuticular projections can be found throughout most of the body of some species in the formicine genus Echinopla Smith, 1857, except on the pygidium, and additionally on the gastral apex of an undescribed species of Strumigenys Smith, 1860 (Myrmicinae: Dacetini). Given that these aforementioned taxa are not closely related to Kempfidris gen. nov., their structures are probably not homologous, but perhaps convergent evolution could be considered, especially in the case of the dacetine ant. Other specialized pygidial structures found in ants are the denticles or spines of Cerapachyinae and the large, upward-curving teeth in Pachycondyla crassinoda (Latreille, 1802) workers, but their position and form are very different. Most members of the solenopsidine group are smooth, with little sculpturing, but this species presents a moderate amount of sculpturing on the head, mesosoma, petiole and postpetiole.
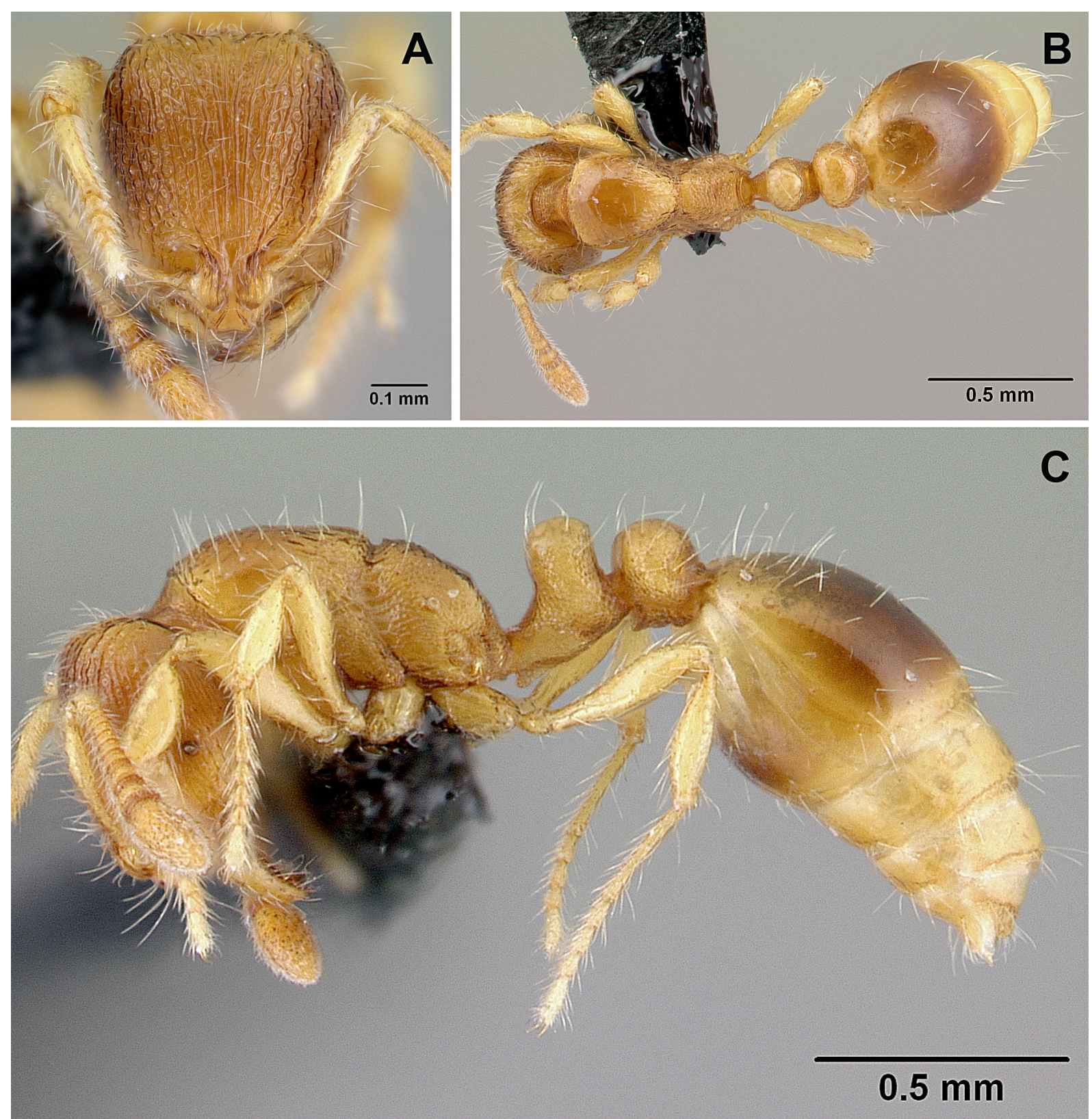

Fig. 3. Kempfidris inusualis (Fernández, 2007) comb. nov., worker from Maroa, Amazonas, Venezuela, specimen CASENT0217050. High-resolution images from AntWeb. A. Head in full face view. B. Body in dorsal view. C. Body in lateral view. Images by Erin Prado. 
Kempfidris inusualis (Fernández, 2007) comb. nov.

Figs $1-3,5$

Monomorium inusuale Fernández, 2007: 135, figs 1-2 (worker).

\section{Material examined}

\section{Holotype}

Worker, Brazil, Bahia, Barrolândia, 16-23 Jul. 1994, S. Lacau (CEPLAC = Laboratorio de Formigas, Centro de Pesquisas de Cacau, Ilheus, Bahia, Brazil).

\section{Paratypes}

1 worker, same data as holotype (ICN); 3 workers, Brazil, Amazonas, Benjamin Constant, 21 Nov. 1962, W.L. Brown Jr. (MZSP); 2 workers, Ecuador, Napo, Limoncocha, 1973, M. Rettenmeyer (MZSP, BMNH). For measurements, see Fernández (2007).

\section{Additional material}

BRAZIL: 12 workers, Rondônia, Porto Velho, Mutum, M7P1, 9³5'44" S 6504'00” W, 8-21 Sep. 2010, R.R. da Silva \& R.M. Feitosa (MZSP); 3 workers, same data (DZUP).

VENEZUELA: 2 workers, Amazonas, Maroa, 120 m, 243'48” N 67³2’34” W, 4 Sep. 2006, J.E. Lattke, JEL3031 (CASC, 1; ICN, 1).

Fig. 4. Father Walter Kempf (19201976). Photographer unknown; files of the Franciscan Order in São Paulo, Brazil. Available from the Global Ant Project website: http:// gap.entclub.org/taxonomists/Kempf/ index.html

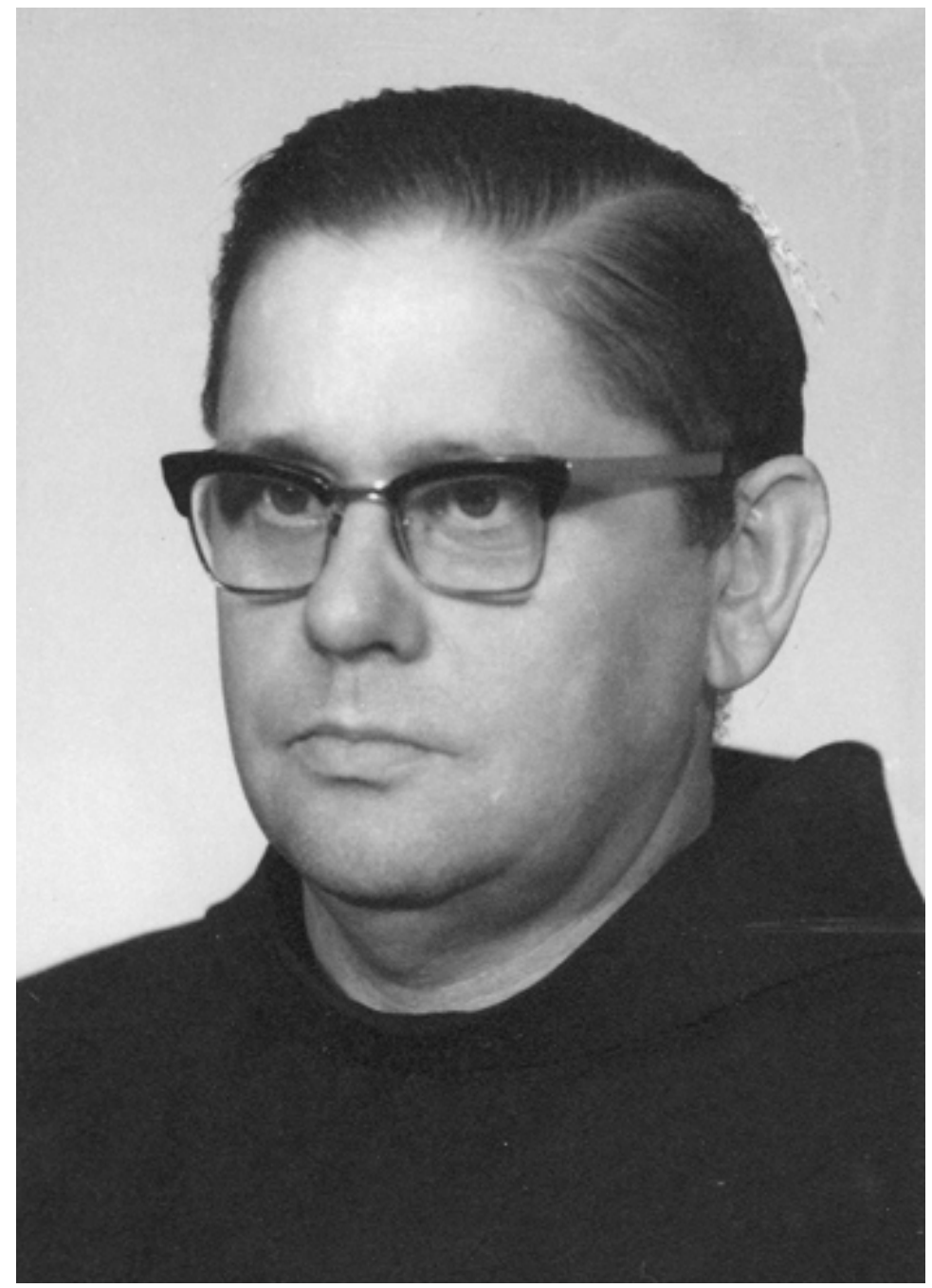




\section{Description (worker)}

Head longer than wide. Sides of head subparallel, slightly wider anteriorly, broadly rounded into posterior border, which is more or less straight. Antennal insertions relatively close together, separated by no more than three times the apical scape width. Scape fails to reach vertexal border.

In lateral view, promesonotum slightly convex, mesonotal margin weakly convex to almost straight. Metanotal groove very deep, well-marked. Propodeal spiracle circular, opened posteriorly. Petiole with peduncle and node well differentiated, the node with subparallel anterior and posterior faces, dorsum convex. Petiolar spiracle at base of node. Petiolar ventral process shaped as rounded, anteroventrally directed tooth. Postpetiole subcampaniform, with a conspicuous transverse, ventral carina. Mandibles, most of promesonotum, dorsum of petiole and postpetiole, and gaster smooth and shining. Head with longitudinal, irregular rugulae mixed with dense foveae. Posterior portion of promesonotum with feeble, short rugulae. Most of mesopleura with irregular, short, longitudinal striae, mixed with fine reticulation.

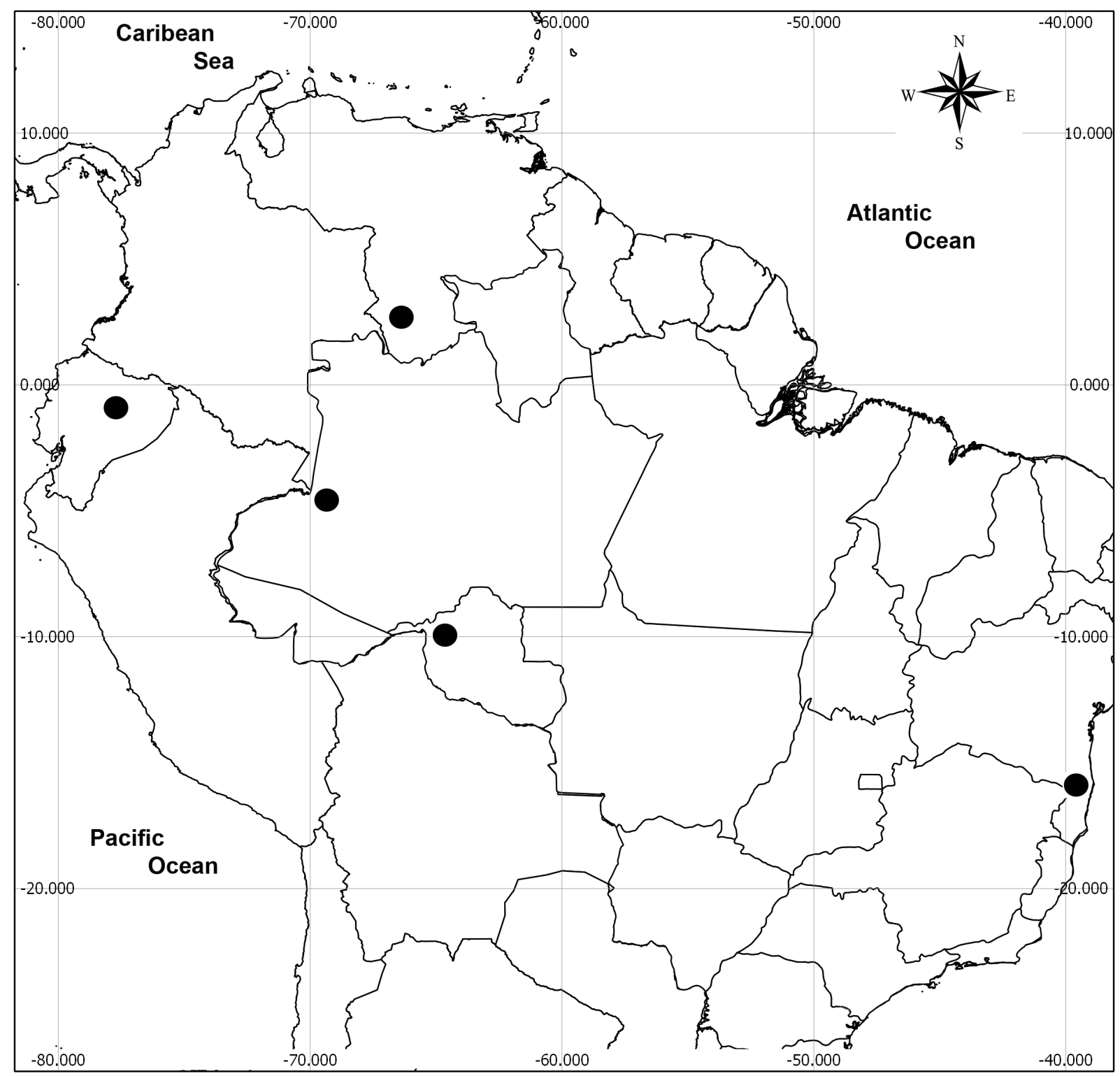

Fig. 5. Distribution map for Kempfidris inusualis (Fernández, 2007) comb. nov. 
Most of propodeum and sides of petiole and postpetiole densely reticulated. Declivity of propodeum with several fine transverse carinae, the most posterior more marked. Moderately erect pilosity on head, promesonotum, petiole, postpetiole and gaster, little on propodeum. Scapes with several erect hairs. Longer hairs about $0.15 \mathrm{~mm}$, those of head shorter. Body light brown to black, appendages lighter.

Queen and male: Unknown.

\section{Distribution}

Brazil, Ecuador and Venezuela (Fig. 5).

\section{Discussion}

Despite the fact that this species is broadly distributed in South America (Fig. 5), records of its occurrence are extremely scarce. Until recently, Kempfidris inusualis comb. nov. was known only from the type series examined by Fernández (2007) and a nest series collected by John Lattke in 2006. Unfortunately, the bulk of this material was left in Venezuela upon Lattke's recent move from the country. However, in 2010 a field expedition (which included R.M. Feitosa) to the southern limits of the Brazilian Amazon Forest (state of Rondônia, near the border with Bolivia) collected a series of K. inusualis comb. nov. workers extracted from a Winkler sample.

Despite its broad distribution, specimens of $K$. inusualis comb. nov. are relatively uniform in size and general aspect. As already mentioned by Fernández (2007), the main differences regarding geographic variation involve slightly distinct propodeal shapes, such as a shorter dorsal face in the Ecuadorian specimens. Specimens from Rondônia, Brazil, differ from other conspecific workers by their darker color (almost black) and more prominent propodeal crests that form small denticles. Given the similarity among the samples examined, we decided to consider these morphological differences as intraspecific variation.

Almost nothing is known about the natural history of $K$. inusualis comb. nov. Most of the specimens studied were apparently obtained from leaf-litter samples. The nest series collected by J. Lattke in the Venezuelan Amazon was obtained from a rotten stick, also harboring a termite nest, on the ground next to an airstrip. The habitat there is open scrub to low trees on white sandy soil that is seasonally flooded by dark, colored waters. Interestingly, all the known samples were collected between July and September, suggesting a more intense activity in this period, which coincides with the low level of the rivers in the Amazon Basin. All things considered, this could also be a collecting artifact, as the aforementioned period approximately coincides with academic holidays in many universities and represents a lower probability of conflict between lectures and field trips.

\section{Acknowledgements}

Dr. Philip Ward (University of California at Davis) for generously sharing unpublished information on the internal phylogeny of Myrmicinae. Brunno Bueno, Bruno Ferrari, and Gabriel Melo (DZUP) for kindly helping with the preparation of the automontage images. The Secretary of Higher Education, Science, Technology and Innovation (SENESCYT) of the Government of Ecuador for supporting J. Lattke's research. To the topic editor of the European Journal of Taxonomy and two anonymous referees for their appropriate corrections and suggestions; one of them provided useful comparative notes regarding the micro-pegs on the abdominal apex.

\section{References}

Billen B. 2009. Diversity and morphology of exocrine glands in ants. In: Proceedings, XIX Simpósio Mirmecologia, Ouro Preto, Brasil, 17-21 Nov. 2009: 1-6. 
Bolton B. 1987. A review of the Solenopsis genus-group and revision of Afrotropical Monomorium Mayr (Hymenoptera: Formicidae). Bulletin of the British Museum (Natural History), Entomology 54: 263-452. http://www.biodiversitylibrary.org/item/127596\#page/1/mode/1up

Bolton B. 2003. Synopsis and classification of Formicidae. Memoirs of the American Entomological Institute 71: 1-370.

Brady S.G., Schultz T.R., Fisher B.L. \& Ward P.S. 2006. Evaluating alternative hypotheses for the early evolution and diversification of ants. Proceedings of the National Academy of Sciences 103: 1817218177. http://dx.doi.org/10.1073/pnas.0605858103

Emery C. 1921. Hymenoptera. Fam. Formicidae. Subfam. Myrmicinae [part]. Genera Insectorum 174A: $1-94$.

Fernández F. 2004. Adelomyrmecini new tribe and Cryptomyrmex new genus of myrmicine ants (Hymenoptera: Formicidae). Sociobiology 44: 325-335.

Fernández F. 2007. Two new South American species of Monomorium Mayr with taxonomic notes on the genus. In: Snelling R.R., Fisher B.L \& Ward P.S. (eds) Advances in Ant Systematics (Hymenoptera: Formicidae): Homage to E. O. Wilson - 50 Years of Contributions. Memoirs of the American Entomological Institute 80: 128-145.

Heterick B.E. 2003. Two new Australian Monomorium Mayr (Hymenoptera: Formicidae), including a highly distinctive species. Australian Journal of Entomology 42: 249-253. http://dx.doi.org/10.1046/ j.1440-6055.2003.00352.X

Keller R.A. 2011. A phylogenetic analysis of ant morphology (Hymenoptera: Formicidae) with special reference to the poneromorph subfamilies. Bulletin of the American Museum of Natural History 355: $1-90$.

Kempf W.W. 1972. Catálogo abreviado das formigas da região Neotropical. Studia Entomologica 15: 3-344.

Moreau C.S. \& Bell C.D. 2013. Testing the museum versus cradle tropical biological diversity hypothesis: phylogeny, diversification, and ancestral biogeographic range evolution of the ants. Evolution 67: 22402257. http://dx.doi.org/10.1111/evo.12105

Moreau C.S., Bell C.D., Vila R., Archibald S.B. \& Pierce N.E. 2006. Phylogeny of the ants: diversification in the age of angiosperms. Science 312: 101-104. http://dx.doi.org/10.1126/science.1124891

Wheeler W.M. 1922. Ants of the American Museum Congo Expedition. A contribution to the myrmecology of Africa. VII. Keys to the genera and subgenera of ants. Bulletin of the American Museum of Natural History 45: 631-710.

Manuscript received: 14 March 2014

Manuscript accepted: 9 May 2014

Published on: 26 May 2014

Topic editor: Koen Martens

Desk editor: Danny Eibye-Jacobsen

Printed versions of all papers are also deposited in the libraries of the institutes that are members of the EJT consortium: Muséum National d'Histoire Naturelle, Paris, France; Botanic Garden Meise, Belgium; Royal Museum for Central Africa, Tervuren, Belgium; National History Museum, London, United Kingdom; Royal Belgian Institute of Natural Sciences, Brussels, Belgium; Natural History Museum of Denmark, Copenhagen, Denmark. 